5 Center for Mental Health and Monitoring of Drugs and Alcohol of the Ministry of Health of Ukraine. Information materials on psychiatric care for 2018. 2018. https://cmhmda.org.ua/ info_materials/ (accessed January 7, 2021).

6 Skokauskas N, Chonia E, van Voren R, Delespaul P, Germanavicius A, Keukens R, et al Ukrainian mental health services and world psychiatric association expert committee recommendations. Lancet Psychiatry 2020; 7(9): 738-40.

7 Sulaberidze L, Green S, Chikovani I, Uchaneishvili M, Gotsadze G. Barriers to delivering mental health services in Georgia with an economic and financial focus: informing policy and acting on evidence. BMC Health Serv Res 2018; 18: 108.

8 Halbreich U, Chkonia E, Okribelashvili N, Karosanidze I, Goginashvili K. Interdisciplinary collaboration in practice: the Georgia process and model. In Advances in Psychiatry (ed. Javed A, Fountoulakis KN): 267-79. Springer, 2019.

9 The Parliament of Georgia, Approval of the State Concept of Mental Health. Georgia Government, 2013 (https://matsne.gov. ge/ka/document/view/2157098?publication=0)

10 Government of Georgia. On Approval of the 2014-2020 State Concept of Healthcare System of Georgia for 'Universal Health Care and Quality Control for the Protection of Patients' Rights'. Georgia Government, 2014 (https://matsne.gov.ge/en/ document/view/2657250?publication=0).

11 Government of Georgia. Approval of the Strategic Document for Mental Health Development and the Action Plan for 2015-2020. Georgia Government, 2014 (https://matsne.gov.ge/ka/ document/view/2667876?publication=0).

12 Government of Georgia. On Amendments to the Resolution 38 638 of the Government of Georgia of December 30, 2016 "On Approval of the State Health Care Programs for 2017”. Georgia
Government, 2017 (https://matsne.gov.ge/ka/document/view/ 3969578?publication=0)

13 Government of Georgia. On Amendments to the Resolution 28828 of the Government of Georgia of December 31, 2020 "On Approval of the State Health Care Programs for 2021". Georgia Government, 2021 (https://matsne.gov.ge/ka/document/view/ 5131689 ?publication=0)

14 Molchanova E. Mental health rehabilitation in the Kyrgyz Republic: official and indigenous models. J Psychosoc Rehabilitation 2014; 1(1): 23-6.

15 Government of the Kyrgyz Republic. PROGRAM of the Government of the Kyrgyz Republic for the protection of mental health of the population of the Kyrgyz Republic for 2018-2030. Ministry of Justice of the Kyrgyz Republic, 2018 (http://cbd. minjust.gov.kg/act/view/ru-ru/11840).

16 Burns T, Catty J, Dash M, Roberts C, Lockwood A, Marshall M. Use of intensive case management to reduce time in hospital in people with severe mental illness: systematic review and meta-regression. BMJ 2007; 335(7615): 336.

17 Iyengar U, Snowden N, Asarnow JR, Moran P, Tranah T, Ougrin D. A further look at therapeutic interventions for suicide attempts and self-harm in adolescents: an updated systematic review of randomized controlled trials. Front Psychiatry 2018; 9: 583.

18 Ougrin D, Zundel T, Corrigall R, Padmore J, Loh C. Innovations in practice: pilot evaluation of the supported discharge service (SDS): clinical outcomes and service use. Child Adolesc Ment Health 2014; 19(4): 265-9.

19 Dieterich $M$, Irving $C B$, Bergman $H$, Khokhar MA, Park B, Marshall $M$. Intensive case management for severe mental illness. Cochrane Database Syst Rev 2017; 1: CD007906.

\title{
MENTAL HEALTH LAW \\ Mental health law in Algeria: new amendments, old concerns
}

\author{
Zoubir Benmebarek $\odot$
}

Private Psychiatrist, Algeria Ministry of Health Population and Hospital Reform, Mila, Algeria. Email: zoubirbenmeb@gmail.com

Keywords. Psychiatry and law; low and middle income countries; human rights; amendment; implementation.

First received 29 Sep 2020 Final revision 18 Feb 2021 Accepted 25 Feb 2021

doi:10.1192/bji.2021.14

(c) The Author(s), 2021. Published by Cambridge University Press on behalf of the Royal College of behalf of the Royal College of
Psychiatrists. This is an Open Access article, distributed under the terms of the Creative Commons Attribution licence (http://creativecommons org/ licenses/by/4.0/), which per ch permits unrestricted re-use, distribution, and reproduction in any medium provided the original work is properly cited.
Since 2018 Algeria has had a new mental health law intended to be more practical and in line with international standards for patients' rights and supervision of coercive measures. Despite its simpler formulation compared with the previous law it remains far from what psychiatrists need and what patients hope for. Some chapters are confusing and difficult to grasp. Like previous mental health laws, it is unlikely that the current law will actually be applied, owing to the huge gap between the core text and the available services.

In 2018 the Ministry of Health of Algeria issued a new health law which, as usual, embedded a section on mental health. It is the third national mental health law since independence in 1962 (the previous law goes back to 1985) and the fourth if we take into account French mental health law that prevailed between 1962 and $1976 .^{1}$
As expected, each enactment of new mental health law engenders hopes of improvements in mental healthcare but also raises doubts over whether those intended improvements will actually follow. So far, no mental health law has ever been effectively and genuinely implemented in the country, or been evaluated and assessed to appraise where it has been successful and where it has fallen short. ${ }^{2}$

The revision process of the new health law has been dragging on for years; the first draft dated back to 2003 at least. ${ }^{3}$ Hopes were high because these amendments, if done properly, would have enabled mental health providers to improve everyday practice and optimise provision of care in accordance with the available services and human resources.

The current law is more concise, its text is clearer and its chapters are more coherent than the previous law. ${ }^{4}$ The changes brought about by this law include improved rights for the mentally ill in relation to involuntary hospitalisation, the 
possibility for a court to order admission of a defendant to hospital for assessment on the recommendation of a forensic psychiatrist and a simpler process for a patient's admission by a third party.

The law comprises three chapters. Each chapter has several sections.

\section{Chapter 1: General provisions}

This chapter deals essentially with the rights of the mentally ill in relation to involuntary hospitalisation. The general rule is that mentally ill patients cannot be admitted to hospital without their consent or the consent of their legal representative (i.e. legal guardian) and involuntary admission is limited to those who cannot give consent and are in need for treatment. Involuntary in-patients, their parents or their appointed legal representatives should be informed of the patients' rights and can directly address the Departmental Mental Health Commission in case of litigation. A new article in the law gives the judge the right to appoint a legal representative for an incapacitous involuntary in-patient who is not under guardianship. A new amendment also requires the approval of the Departmental Mental Health Commission to admit patients under 16 years or over 75 years of age. This departmental commission, which comprises a wali (appointed civil governor) representative, two psychiatrists and a member of an independent patient representative group (instead of a court judge under the previous law), monitors and supervises involuntary hospitalisation and reviews requests and claims (in case of litigation) in relation to mentally ill patients; its decisions are enforceable.

\section{Chapter 2: Hospital admission}

The different kinds of hospital admission are as follows.

(a) Voluntary admission.

(b) Admission by a third party for psychiatric observation and admission by a third party: these forms of admission concern mentally ill persons who need in-patient care and cannot give consent. It was devised as a stepped-care model (observation then admission) especially for patients unknown to the healthcare system. A hospital psychiatrist will carry out and monitor the whole procedure. In the former law these admissions were indistinct and overlapped, with no time limit for either.

(i) Admission for psychiatric observation by a third party: furthered at a request of a relative, legal representative or public authority (mayor, wali, police officer). The patient is admitted for up to 15 days, at which point they are either discharged or kept another 15 days. They may be discharged before this time if they improve.

(ii) Admission by a third party: admission by a third party for psychiatric observation can be transformed at any moment in admission by a third party if needed following a psychiatric assessment. To be lawful it needs a written request by a family member (grandparent, parent, offspring, sibling, spouse uncle, aunt) or the patient's legal representative and should be reported on a special record forwarded to the hospital administration. The patient is discharged on a psychiatrist's decision at the written request of the patient, of the person who has brought about the admission, of a relative's demand or the patient's legal representative.

(c) Compulsory psychiatric examination, compulsory psychiatric observation and compulsory hospital admission: this section relates to dangerous psychiatric patients who need to be kept in closed wards; observation means a time-limited admission. In the previous law there was no compulsory psychiatric observation and it was the patient's relatives, not the patient, who could contest compulsory admission. The procedures take effect after one hospital psychiatrist's decision.

(i) Compulsory psychiatric examination: in case of psychiatric dangerousness, a wali or a general prosecutor can ask for a compulsory psychiatric examination. The assessment is made in a hospital by a psychiatrist, who can order compulsory psychiatric observation whenever it is needed.

(ii) Compulsory psychiatric observation: admission for this purpose lasts up to 15 days, at the end of which the patient is discharged, voluntarily admitted, admitted at the request of a third party or compulsorily admitted.

(iii) Compulsory admission is triggered during or after a voluntary admission, admission by a third party for psychiatric observation or a compulsory psychiatric observation. The decision for compulsory admission is issued by a wali on the basis of a medical certificate (e.g. dangerousness, patient refusing treatment), lasts for a maximum of 6 months and is renewable. If the patient contests the decision, they address a letter to the Departmental Mental Health Commission. Before discharge the psychiatrist must inform the wali, who can either approve or countermand the decision.

(d) Forensic evaluation and hospital admission: this new item states that, whenever needed, a forensic psychiatrist appointed by a court to determine criminal responsibility for a mentally ill defendant can order 
a compulsory psychiatric observation or compulsory hospital admission in a highsecurity hospital (affiliated to the Ministry of Health and dedicated to individuals deemed not guilty by reason of insanity) to undergo a thorough forensic assessment in case of difficulties in proving legal insanity. Formerly, admission to high-security hospitals was limited to those already found not guilty by reason of insanity (there is no trial for such patients in the Algerian judicial system).

\section{Chapter 3: Supervision measures during involuntary hospital admission}

The wali and the prosecutor should regularly be informed about involuntarily admitted patients. The closed wards admitting involuntary patients have to provide a patient record approved by a judge and reviewed twice a year by the wali and the prosecutor. The wali and the prosecutor can, at any time, require a report of any patient from the psychiatrist.

\section{Discussion}

At first glance, the current law seems innovative compared with previous ones in regard to its simple and practical formulation of different kinds of hospital admission and its emphasising of the rights of the mentally ill. But a close look unveils confusion and ambiguity, which have been two core characteristics of previous laws. For instance, it does not give details about the patient's rights and the role of the legal representative is unclear. There is also a confusion between two kinds of involuntary admission/observation (compulsory and by a third party) and a blurred and overlapping monitoring role of the administration (wali) and justice (prosecutor/judge).

Besides, the major question is whether the law will be applied or not. During the process of law revision and argumentation, little has been done to appraise the previous law or to broaden participation to all people involved in the care of persons with mental disorders (such as mental health professionals, lawyers, patient representative groups, civil rights movements, patients and relatives, court and administration staff) and there have been no in-depth published reports about assessment of the previous laws, although several seminars have been organised to that purpose. $^{5}$

Inadequacy between the text of a law and reality on the ground is a significant hurdle to its enforcement. As Kacha ${ }^{2}$ puts it, commenting on the previous mental health law: mental health law provisions cannot be applied without appropriate psychiatric services and infrastructure. Nothing has changed since that observation was made and this issue is still relevant today.

The Departmental Mental Health Commission is highly illustrative of the impediments to the implementation of the law. Despite its importance in monitoring coercive measures and defending the rights of mentally ill people, the government has not yet set up this commission. Under 33 years of mental health legislation this commission never came into being.

Another problem is the lack of coordination between hospitals, administrations (mayor, wali), police and the justice department in managing coercive measures. A report published by the Ministry of Heath recognises that overcoming the lack of coordination and cooperation between forensic and administrative sectors is the main challenge facing a genuine implementation of mental health policies. ${ }^{6}$

Furthermore, shortages of psychiatric beds (13.1 beds per 100000$)^{6}$ and the lack of alternatives other than full hospital admission puts hospitals under a huge pressure to meet the needs of an evergrowing demand. Hospitals try to manage that by admitting only psychiatric emergencies and for a limited time to allow the best turn-over. For instance, all decisions pertaining to admission and discharge are solely taken with the hospital psychiatrist's approval, except the compulsory admissions. No written procedures are needed. Involuntary admissions are not recorded, and there is no formal or regular connection between hospital, administration and justice to manage compulsory admissions.

To be efficient a law ought to be practical, easy to implement and stem from the experiences of everyday practice. This requires a thorough and genuine appraisal of actual practices and related issues, an accurate assessment of mental health resources and the nature of input that police staff, justice and welfare services can make to assist the mental health system. Policymakers should then build on these data to draft a simpler and more suitable law (i.e. to keep only three kinds of hospital admission: voluntary, involuntary (need for care, lack of consent) and compulsory (dangerousness); to remove psychiatric observation (a redundant, confusing term); to allow only courts to order and monitor involuntary/ compulsory admission; and so on). It will be a daunting and time-consuming task but it is worth it if we are to achieve good outcomes in managing mental health problems in a middleincome country.

\section{Data availability}

Data availability is not applicable to this article as no new data were created or analysed in this study.

\section{Funding}

This research received no specific grant from any funding agency, commercial or not-for-profit sectors.

\section{Declaration of interest}

Z.B. is a private psychiatrist affiliated to the Algerian Ministry of Health, Population and Hospital Reform. 


\section{References}

1 Bakiri A. La législation psychiatrique algérienne. Historique et actualités [Algerian psychiatric law: past and present]. Le Lien Psy 2008; 1: 61-2.

2 Kacha F. La psychiatrie en Algérie [Psychiatry in Algeria]. L'Infor Psychiatr 2005; 81: 145-8.

3 Ministry of Heath, Population and Hospital Reform. Avant projet de loi sanitaire version provisoire soumise à concertation - Février 2003 [Preliminary draft health law, provisional version submitted for consultation - February 2003]. Ministry of Health, Population and Hospital Reform, 2004. Available from: http://www. santemaghreb.com/algerie/loisanit3.htm [cited 13 Jun 2020].
4 Benmebarek Z. Mental health legislation in Algeria. BJPsych Int 2017; 14: 12-5.

5 Kaddar M. Projet de loi sanitaire: des avancées et des questions [The Health Bill: progress and questions]. Quot d'Oran, 5 Jan 2017 (http://www.lequotidien-oran.com/?news=5238478).

6 Ministry of Heath, Population and Hospital Reform. Promotion de la santé mentale en Algérie: faire face aux nouveaux défis, développer des réponses adaptées [Promotion of mental health in Algeria: facing new challenges, developing evidence-based intervention]. Ministry of Health, Population and Hospital Reform, 2018 (https://www.sante.gov.dz/images/Prevention/ MH_Policy_Brief.pdf [cited 12 June 2020]).
MENTAL HEALTH LAW PROFILE

\title{
Mental health law in Nepal
}

\author{
Rakesh Singh $^{1} \odot$ and Seema Khadka
}

${ }^{1}$ Independent Mental Health Researcher, and Visiting Faculty Member, Department of Public Health, KIST Medical College, Tribhuvan University, Kathmandu, Nepal. Email: rakes4r@gmail.com

${ }^{2}$ Alumnus Public Health Student, School of Public Health, Patan Academy of Health Sciences, Lalitpur, Nepal

Keywords. Mental health; mental health law; mental health legislation; mental health policy;

lation;

First received 2 Jul 2021

Final revision 22 Jul 2021

Accepted 1 Aug 2021

doi:10.1192/bji.2021.52

(c) The Author(s), 2021. Published by Cambridge University Press on behalf of the Royal College of Psychiatrists. This is an Open Access article, distributed under the terms of the Creative the terms of the Creative
Commons Attribution licence Commons Attribution licence
(https://creativecommons.org/ licenses/by/4.0/), which permits unrestricted re-use, distribution, and reproduction in any $r$ and ginal work is properly cited.

\section{During the past three decades Nepal has gone through series of reforms to address the mental health needs of the Nepalese population by promulgation of an exclusive National Mental Health Policy and related Strategic Action Plan. Small but significant improvements have been achieved in Nepal with regard to mental health policies and plans. This article discusses the evolution of mental health policies in Nepal and analyses the challenges to be overcome for their effective implementation.}

\section{Background}

Mental illness accounts for $7 \%$ of the global burden of disease as measured in disability-adjusted life years and $19 \%$ of all years lived with disability. ${ }^{l}$ Many low- and middle- income countries (LMICs) lack high-quality mental health services and have a higher prevalence of misdiagnosis and symptomatic treatment. The median number of psychiatrists per 100000 populations is only 0.1 in LMICs. ${ }^{2}$ Although mental health policy is a vital tool, only $60 \%$ of member countries of the World Health Organization (WHO) have mental health policies; $71 \%$ have mental health plans; and $59 \%$ possess mental health legislation. ${ }^{2}$ The population covered by mental health legislation is very low in LMICs $(36 \%)$ compared with high-income countries $(92 \%){ }^{2}$

\section{Mental health in Nepal}

The first epidemiological survey in Kathmandu, the capital city of Nepal, in 1984 showed that around $14 \%$ of the city's population had a mental illness. A pilot study of the National Mental Health Survey in 2018 reported the prevalence of mental disorders to be $12.9 \%^{3}$ and the actual burden is expected to be more at national level. However, there is only one public psychiatric hospital in Nepal. Moreover, there has been no significant rise in the mental healthcare budget for many years: it accounts for less than $1 \%$ of total national health expenditure, with the major proportion directed towards the mental hospital. To improve mental health and reduce the burden of mental disorders, a high-quality mental health service achieved through promulgation of mental health policies is required.

In 1975 , the WHO stated that detection and management of mental disorders should be the tasks of primary healthcare workers. In 2015, the United Nations' Sustainable Development Goals prioritised mental health and its promotion. In this regard, Nepal has shown commitment to attainment of a basic level of mental healthcare for Nepalese citizens. Nepal's 15th Five-Year Plan (2019-2024) includes provision of access to mental health service for everyone. The Epidemiology and Disease Control Division of the Department of Health Services was designated as a focal unit to oversee mental healthcare in 2018 and mental health programmes were operationalised by the Non-Communicable Disease and Mental Health Section. Despite challenges and barriers, significant incremental improvements have been achieved in Nepal with regard to mental health by endorsement of the policies and strategies in different periods.

The 1996 National Mental Health Policy In 1996 a comprehensive mental health policy was formulated and incorporated in the 9th Five-Year Plan. Its main goal was to provide at least a minimum level of mental healthcare to all Nepalese. The key components of the plan were: ensuring availability and accessibility of 